\title{
Coordinated transcriptional and translational control in metabolic homeostasis in flies
}

\author{
Paul Lasko ${ }^{1}$ and Nahum Sonenberg ${ }^{2,3}$ \\ ${ }^{1}$ Department of Biology and Developmental Biology Research Initiative, McGill University, Montréal, Québec H3A 1B1, \\ Canada; ${ }^{2}$ Department of Biochemistry and McGill Cancer Centre, McGill University, Montréal, Québec H3G 1Y6, Canada
}

In eukaryotes, transcription and translation occur in separate cellular compartments. This complicates the cell's ability to coordinate these two steps of gene expression. Clearly, a certain degree of coordination between transcription and translation must occur. Under stress conditions such as starvation or high oxygen radical concentration, general translation is inhibited, yet some mRNAs continue to be translated, because they harbor certain structural features (Holcik and Sonenberg 2005). Some genes are transcriptionally up-regulated under stress conditions. Until now, no precise mechanism has been demonstrated to explain how these up-regulated mRNAs are efficiently translated.

In a recent paper in Genes \& Development, Marr et al. (2007) provide evidence that coordination of transcription and translation involves interplay between cap-dependent and cap-independent mechanisms of translation. Importantly, they report that the same signaling pathway controls both the transcriptional and translational regulatory mechanisms. The system they studied is the metabolic response of Drosophila larvae to nutrient depletion. Under such conditions, the larvae mount a survival response by dramatically down-regulating their metabolism to save on energy. One of the most energy-consuming processes in the cell is translation. Thus, under conditions of limiting energy supply, translation is decreased.

The initiation step is the major target for controlling translation rates through phosphorylation of initiation factors and their regulators. In general, translation initiation in eukaryotes is strongly facilitated by the presence of the cap structure $\left(\mathrm{m}^{7} \mathrm{GpppN}\right.$, where $\mathrm{N}$ is any nucleotide), which is referred to as the "cap" (Shatkin 1976). The cap is present on all nuclear-transcribed mRNAs. It stimulates translation by recruiting the initiation factor eIF4F complex that consists of eIF4E, the cap-binding protein; eIF4A, an RNA helicase that is

${ }^{3}$ Corresponding author.

E-MAIL nahum.sonenberg@mcgill.ca; FAX (514) 398-7274.

Article is online at http://www.genesdev.org/cgi/doi/10.1101/gad.1524707. thought to melt the mRNA 5' secondary structure; and eIF4G, a modular scaffolding protein. eIF4G binds to several proteins, including eIF3, which binds the 40S ribosomal subunit. Thus, eIF4G bridges the mRNA and the ribosome (Pestova et al. 2007). An alternative mechanism of translation, which is independent of the cap, also exists. In this situation, the ribosome binds at an internal site, which is termed the IRES (internal ribosome entry site). Cap-independent translation was first established for picornavirus viral mRNAs (Jang et al. 1988; Pelletier and Sonenberg 1988), which do not possess a cap, but examples of cap-independent translation have now been documented for some capped cellular mRNAs (Elroy-Stein and Merrick 2007).

Cap recognition can be inhibited by a family of eIF4Ebinding proteins (4E-BPs). These proteins are conserved in most metazoans (excluding Caenorhabditis elegans). 4E-BPs inhibit cap-dependent translation by binding to eIF4E at the eIF4G-binding site and thus preventing the formation of the eIF4F complex. Thus, they are potent repressors of cap-dependent translation. However, because IRES-promoted translation is independent of the cap structure, this mode of translation is refractory to inhibition by $4 \mathrm{E}-\mathrm{BPs}$. The interaction between eIF4E and the 4E-BPs is modulated by phosphorylation of the 4EBPs. Hypophosphorylated 4E-BPs bind tightly to eIF4E, whereas phosphorylation of 4E-BPs results in their dissociation from eIF4E. The 4E-BPs are phosphorylated on multiple sites (at least five), and the release of 4E-BPs from eIF4E requires phosphorylation on four sites (Hay and Sonenberg 2004). The identities of all the relevant 4E-BP kinases are not known, but two priming phosphorylation sites are directly phosphorylated by TOR (target of rapamycin) kinase. TOR is activated by phosphoinositide-3-kinase (PI3K)/Akt signaling in response to multiple extracellular stimuli including growth factors, hormones, amino acids, and mitogens. It is suppressed by conditions such as hypoxia and low levels of energy or amino acid depletion. Upon activation, TOR enhances anabolic processes such as synthesis of proteins and ribosome biogenesis, while upon inhibition, it promotes catabolic processes such as starvation-induced 
gene transcription and autophagy. Consistent with its major role in the control of cell homeostasis, TOR was shown to manifest significant effects on organismal survival under stress, longevity (Jia et al. 2004; Kapahi et al. 2004), and involvement in diseases such as cancer (Sabatini 2006).

How does TOR do all these things? TOR has several phosphorylation targets in addition to 4E-BPs; the most prominent of them being the S6K (ribosomal protein S6) kinases. However, 4E-BPs are major mediators of TOR activity, and many of the phenotypes associated with genetic manipulation of 4E-BPs are similar to those resulting from perturbations of the PI3K/Akt/TOR signaling pathway. Drosophila has been an especially valuable organism for studying the role of 4E-BP in metabolic homeostasis and development, in part because in flies only one gene ( $d 4 E-B P$, also known as Thor) encodes 4E-BP. Mammals produce three closely related forms of 4E-BP from different genes. $d 4 E-B P$-null mutant flies exhibit a shortened life span (Tettweiler et al. 2005). Conversely, overexpression of FOXO, or a dominant-negative form of dTOR, or the TOR inhibitors TSC1 and TSC2 results in an extended life span (Accili and Arden 2004; Kapahi et al. 2004). In Drosophila, hypomorphic dTOR mutants have decreased lipid and glucose levels, and an increased life span (Luong et al. 2006). $d 4 E-B P$ mutants also have reduced viability upon exposure to oxidative stress or food depletion, similar to the phenotype observed in foxo mutants. Intriguingly, these mutants fail to reduce their lipid catabolism appropriately upon starvation; conversely, transgenic flies expressing a nonphosphorylatable constitutively active form of d4E-BP accumulate excess fat (Teleman et al. 2005). The most compelling evidence that d4E-BP is a major mediator of the function of $\mathrm{dFOXO}$ in stress resistance is that ectopic expression of d4E-BP in foxo-null flies rescues their resistance to oxidative stress (Tettweiler et al. 2005). What, then, is the molecular basis for this phenomenon? dFOXO is a transcription factor that activates $d 4 E-B P$ transcription (Junger et al. 2003; Puig et al. 2003). Active dAkt phosphorylates dFOXO and prevents its entry into the nucleus (Brunet et al. 1999). Thus, under favorable growth conditions, dFOXO cannot activate $d 4 E-B P$ transcription (Fig. 1).

Under nonfavorable growth conditions, such as the absence of insulin, dFOXO is activated and elevates the transcription of d4E-BP and insulin receptor (Puig et al. 2003; Puig and Tjian 2005). This is presumably an adaptive response to nonfavorable growth conditions, as d4EBP inhibits mRNA translation, which consumes energy, while elevated expression of insulin receptor sensitizes the cells to even low levels of insulin. However, one question that emerged was how the newly transcribed insulin receptor mRNA is translated in the presence of excess amounts of d4E-BP. In answering this question, Marr et al. (2007) first showed that Drosophila produces three mRNAs from different promoters that encode the insulin-like receptor (dINR). All three $\operatorname{dINR}$ mRNAs have long 5' untranslated regions with multiple AUG codons upstream of the authentic translation start site. They demonstrated, using several independent assays in cultured cells and a cell-free system derived from Drosophila embryos, that all three $d I N R$ mRNAs have functional IRES elements, and can thus be translated in a cap-independent manner. They found that addition of a cap analog $\left(\mathrm{m}^{7} \mathrm{GpppG}\right)$ or d4E-BP to an in vitro translation extract resulted in increased $d I N R$ mRNA translation. Thus, Marr et al. provide further evidence for a central role of d4E-BP in metabolic homeostasis.

Marr et al. (2007) propose that this mechanism of regulating dINR expression, which couples dFOXO-mediated transcriptional activation with a means of overcoming the translational repression mediated by another $\mathrm{dFOXO}$ target, d4E-BP, may serve to amplify the insulin signal.
Figure 1. In the absence of insulin (insulinlike peptides in Drosophila [dILPs]), dFOXO is hypophosphorylated and activated, which in turn activates transcription of $d I N R$. dFOXO also activates transcription of $d 4 E-B P$, and $\mathrm{d} 4 \mathrm{E}-\mathrm{BP}$ is hypophosphorylated because the PI3K pathway is down-regulated in the absence of dILPs. dTOR also regulates PI3K activity. Hypophosphorylated d4E-BP inhibits cap-dependent translation by binding to eIF4E and sequestering it away from eIF4G. However, the dINR mRNAs escape this inhibition because each is translated from an IRES.




Therefore, when faced with a paucity of nutrients, the fly exploits a sophisticated mechanism to optimize the production of dINR to supply energy to the cell. This mechanism provides a rare example of coordination between transcription and translation in eukaryotes, although one may easily predict that other mRNAs whose expression is up-regulated under stress conditions may be similarly regulated. This study also provides the first example in which down-regulation of cap-dependent translation is associated with up-regulation of cellular IRES-dependent mRNA translation in vivo, although this has previously been demonstrated in extracts for cap-independent translation of viral mRNAs (Svitkin et al. 2005).

Is the INR transcriptional-translational feedback loop functioning in vertebrates? Consistent with this possibility, the mRNA encoding insulin-like growth factor I receptor in rats contains a functional IRES and can be translated in the presence of rapamycin, a strong inhibitor of TOR and thus of cap-dependent translation (Giraud et al. 2001). Furthermore, Puig and Tjian (2005) reported that the amounts of insulin receptor in mouse muscle cells are regulated by FOXO primarily at the post-transcriptional level. It would be of great interest therefore to determine if FOXO activates one or all of the 4E-BPs in vertebrates. If so, this would shed new light on the role of $4 \mathrm{E}-\mathrm{BPs}$ in metabolic diseases such as diabetes and obesity.

\section{Acknowledgments}

We thank Nissim Hay, Gritta Tettweiler, Olivier Le Bacquer, and Emmanuel Petroulakis for comments. Work in the our laboratories was supported from grants from the Canadian Institute of Health Research (CIHR).

\section{References}

Accili, D. and Arden, K.C. 2004. FoxOs at the crossroads of cellular metabolism, differentiation, and transformation. Cell 117: 421-426.

Brunet, A., Bonni, A., Zigmond, M.J., Lin, M.Z., Juo, P., Hu, L.S., Anderson, M.J., Arden, K.C., Blenis, J., and Greenberg, M.E. 1999. Akt promotes cell survival by phosphorylating and inhibiting a Forkhead transcription factor. Cell 96: 857-868.

Elroy-Stein, O. and Merrick, W.C. 2007. Translation initiation via cellular internal ribosome entry sites. In Translational control in biology and medicine (eds. M.B. Mathews et al.), pp. 155-172. Cold Spring Harbor Laboratory Press, Cold Spring Harbor, NY.

Giraud, S., Greco, A., Brink, M., Diaz, J.-J., and Delafontaine, P. 2001. Translation initiation of the insulin-like growth factor I receptor mRNA is mediated by an internal ribosome entry site. J. Biol. Chem. 276: 5668-5675.

Hay, N. and Sonenberg, N. 2004. Upstream and downstream of mTOR. Genes \& Dev. 18: 1926-1945.

Holcik, M. and Sonenberg, N. 2005. Translational control in stress and apoptosis. Nat. Rev. Mol. Cell Biol. 6: 318-327.

Jang, S.K., Krausslich, H.G., Nicklin, M.J., Duke, G.M., Palmenberg, A.C., and Wimmer, E. 1988. A segment of the 5' untranslated region of encephalomyocarditis virus RNA directs internal entry of ribosomes during in vitro translation. $J$.
Virol. 62: 2636-2643.

Jia, K., Chen, D., and Riddle, D.L. 2004. The TOR pathway interacts with the insulin signaling pathway to regulate $C$. elegans larval development, metabolism, and life span. Development 131: 3897-3906.

Junger, M.A., Rintelen, F., Stocker, H., Wasserman, J.D., Vegh, M., Radimerski, T., Greenberg, M.E., and Hafen, E. 2003. The Drosophila forkhead transcription factor FOXO mediates the reduction in cell number associated with reduced insulin signaling. J. Biol. 2: 20.

Kapahi, P., Zid, B.M., Harper, T., Koslover, D., Sapin, V., and Benzer, S. 2004. Regulation of lifespan in Drosophila by modulation of genes in the TOR signaling pathway. Curr. Biol. 14: 885-890.

Luong, N., Davies, C.R., Wessells, R.J., Graham, S.M., King, M.T., Veech, R., Bodmer, R., and Oldham, S.M. 2006. Activated FOXO-mediated insulin resistance is blocked by reduction of TOR activity. Cell Metab. 4: 133-142.

Marr II, M.T., D'Alessio, J.A., Puig, O., and Tjian, R. 2007. IRESmediated functional coupling of transcription and translation amplifies insulin receptor feedback. Genes \& Dev. 21: 175-183.

Pelletier, J. and Sonenberg, N. 1988. Internal initiation of translation of eukaryotic mRNA directed by a sequence derived from poliovirus RNA. Nature 334: 320-325.

Pestova, T.V., Lorsch, J.R., and Hellen, C.U.T. 2007. The mechanism of translation initiation in eukaryotes. In Translational control in biology and medicine (eds. M.B. Mathews et al.), pp. 87-128. Cold Spring Harbor Laboratory Press, Cold Spring Harbor, NY.

Puig, O. and Tjian, R. 2005. Transcriptional feedback control of insulin receptor by dFOXO/FOXO1. Genes \& Dev. 19: 24352446.

Puig, O., Marr, M.T., Ruhf, M.L., and Tjian, R. 2003. Control of cell number by Drosophila FOXO: Downstream and feedback regulation of the insulin receptor pathway. Genes \& Dev. 17: 2006-2020.

Sabatini, D.M. 2006. mTOR and cancer: Insights into a complex relationship. Nat. Rev. Cancer 6: 729-734.

Shatkin, A.J. 1976. Capping of eucaryotic mRNAs. Cell 9: 645653.

Svitkin, Y.V., Herdy, B., Costa-Mattioli, M., Gingras, A.-C., Raught, B., and Sonenberg, N. 2005. Eukaryotic translation initiation factor 4E availability controls the switch between cap-dependent and internal ribosomal entry site-mediated translation. Mol. Cell. Biol. 25: 10556-10565.

Teleman, A.A., Chen, Y.W., and Cohen, S.M. 2005. 4E-BP functions as a metabolic brake used under stress conditions but not during normal growth. Genes \& Dev. 19: 1844-1848.

Tettweiler, G., Miron, M., Jenkins, M., Sonenberg, N., and Lasko, P.F. 2005. Starvation and oxidative stress resistance in Drosophila are mediated through the eIF4E-binding protein, d4E-BP. Genes \& Dev. 19: 1840-1843. 


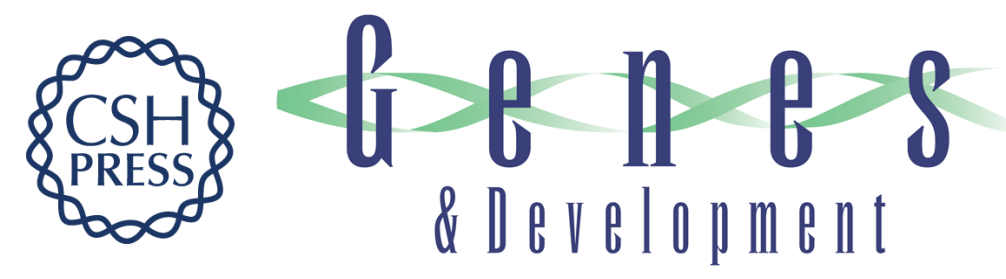

\section{Coordinated transcriptional and translational control in metabolic homeostasis in flies}

Paul Lasko and Nahum Sonenberg

Genes Dev. 2007, 21:

Access the most recent version at doi:10.1101/gad.1524707
Related Content IRES-mediated functional coupling of transcription and translation amplifies insulin receptor feedback
Michael T. Marr II, Joseph A. D'Alessio, Oscar Puig, et al.
Genes Dev. January , 2007 21: 175-183
References This article cites 19 articles, 10 of which can be accessed free at:
http://genesdev.cshlp.org/content/21/3/235.full.html\#ref-list-1
Articles cited in:
http://genesdev.cshlp.org/content/21/3/235.full.html\#related-urls

\section{License}
Email Alerting
Service
Receive free email alerts when new articles cite this article - sign up in the box at the top right corner of the article or click here.

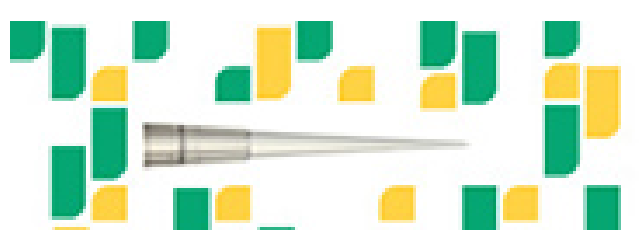

Focused on your science. 